\title{
Family size limitation: a method for demonstrating recessive inheritance
}

\author{
J F Y BROOKFIELD*, R J POLLITT †, AND I D YOUNG \\ From the Departments of Genetics* and Child Health $\neq$, University of Leicester; and the Regional Neonatal \\ Screening Laboratory, Middlewood Hospital, Sheffield.
}

SUMMARY Limitation of family size after the birth of a child with a serious disorder poses a problem in demonstrating autosomal recessive inheritance. In this paper methods are presented for distinguishing autosomal recessive inheritance given a $100 \%$ deterrent effect, and revealing a partial deterrent effect by analysis of sibship size and comparison with general population data. These methods are illustrated using information from phenylketonuria families.

Segregation analysis, as used in establishing or confirming autosomal recessive inheritance, is based on derivation of a segregation ratio from sibships, some of which contain more than one affected subject. Thus, when ascertainment is complete, tests using the truncate binomial, such as the 'a priori' and 'maximum likelihood' methods, can be used. When ascertainment is incomplete, other tests such as the 'sib' and 'proband' methods can be used. These approaches are discussed at length by Emery. ${ }^{1}$ If, however, a disorder is so severe in its effects upon the child or the burden imposed upon the family that parents are always deterred from further childbearing, then no sibship will contain more than one affected child. Consequently, autosomal recessive inheritance will not be obvious. Alternatively, the disorder may be less severe and exert only a partial deterrent effect. This will tend to produce an artificially low segregation ratio using the aforementioned methods of analysis. In this paper we consider ways in which these problems can be tackled and try to illustrate these using data for phenylketonuria derived from the Trent Regional Neonatal Screening Programme.

\section{Methods}

COMPLETE DETERMENT

If all parents are deterred from further childbearing by the birth of an affected child, then all sibships will contain only one affected child who will be the last born in the sibship. This will apply regardless of the cause of the disorder, whether autosomal recessive or environmental. Thus, the data will consist of a set of sibships each containing one affected child and a variable prior number of unaffected children. An indication of the probable aetiology can be obtained by analysis of the family size distribution and comparison with family size distribution in unaffected families. To do this it is necessary to know the empirical probabilities that a couple with $\mathrm{X}$ children will have future children. These are referred to as $r_{x}$. These values can be obtained from the observed family size distribution in unaffected families representative of the population from which the affected sibships have been obtained.

For the general population the proportion of families with $\mathrm{X}$ children are:

$$
\begin{array}{ll}
X & \text { Proportion of families } \\
1 & 1-r_{1} \\
2 & r_{1}\left(1-r_{2}\right) \\
3 & r_{1} r_{2}\left(1-r_{3}\right) \\
n & r_{1} \ldots r_{n-1}\left(1-r_{n}\right) .
\end{array}
$$

If the disease is autosomal recessive there will be a certain proportion of families in which both parents are heterozygotes, and the probability, $p$, that any child of one of these couples will be affected is $0 \cdot 25$. In this situation the proportions of such families with $\mathrm{X}$ children will be:

$$
\begin{array}{ll}
X & \begin{array}{l}
\text { Proportion of families } \\
\text { of two heterozygous parents }
\end{array} \\
1 & p \\
2 & r_{1}(1-p) p \\
3 & r_{1} r_{2}(1-p)^{2} p \\
n & r_{1} \ldots \ldots r_{n-1}(1-p)^{n-1} p .
\end{array}
$$


If the condition is non-genetic, then the probability of any child being affected can be labelled as Z (a very small number). In this situation the proportion of families with $\mathrm{X}$ children will be:

$\begin{array}{ll}\mathrm{X} & \text { Proportion of families } \\ 1 & \mathrm{Z} \\ 2 & \mathrm{Z} \mathrm{r}_{1} \\ 3 & \mathrm{Z} \mathrm{r}_{1} \mathrm{r}_{2} \ldots . \mathrm{r}_{\mathrm{n}-1} .\end{array}$

Values of $r_{1}, r_{2}$, and $r_{3}$ can be obtained from published tables of previous liveborn children. Values for 1980 for all births in England and Wales were $^{2}$ :

First born $\quad 240975$

Second born 209164 Therefore $\quad r_{1}=0.87$

$\begin{array}{lll}\text { Third born } & 86336 & \mathrm{r}_{2}=0.41\end{array}$

$\begin{array}{lll}\text { Fourth born } 27537 & r_{3}=0.32\end{array}$

Fifth born +14850 (and assume $r_{4}=0 \cdot 25$ ).

These formulae thus predict that affected families will be smaller than usual and this effect will be particularly strong if the condition is autosomal recessive.

$\begin{array}{llll}\begin{array}{l}\text { Sibship } \\ \text { size }\end{array} & \begin{array}{l}\text { Unaffected } \\ \text { families (\%) }\end{array} & \begin{array}{l}\text { Affected } \\ \text { autosomal } \\ \text { recessive } \\ (\%)\end{array} & \begin{array}{l}\text { Affected } \\ \text { environmental } \\ (\%)\end{array} \\ & & & \\ 1 & 13 & 53 & 43 \\ 2 & 53 & 34 & 37 \\ 3 & 25 & 10 \cdot 5 & 15 \\ 4 & 9 & 2 \cdot 5 & 5\end{array}$

Thus simple inspection of the observed family size distributions may give a useful indication of the probable aetiology. An additional means of distinguishing between the two alternatives of a genetic and a non-genetic cause is provided by the following. For the environmental aetiology, the ratio of the number of affected families with $\mathrm{n}$ offspring to the number with one offspring is $r_{1} r_{2} r_{3} \ldots . r_{n-1}$, which is the same as the proportion of families in the general population with $n$ or more offspring. If the disorder is autosomal recessive the ratio is $r_{1} r_{2} r_{3} \ldots$ $r_{n-1}(1-p)^{n-1}$. If the observed ratio is divided by the proportion of general population families of size $n$ or larger, the natural logarithm of the resulting value can be plotted against $\mathrm{n}$ as shown in fig 1 . A horizontal line would be expected in the environmental case, and a line of negative slope $(-0 \cdot 287$, that is, natural $\log$ of 0.75 ) in recessive inheritance.

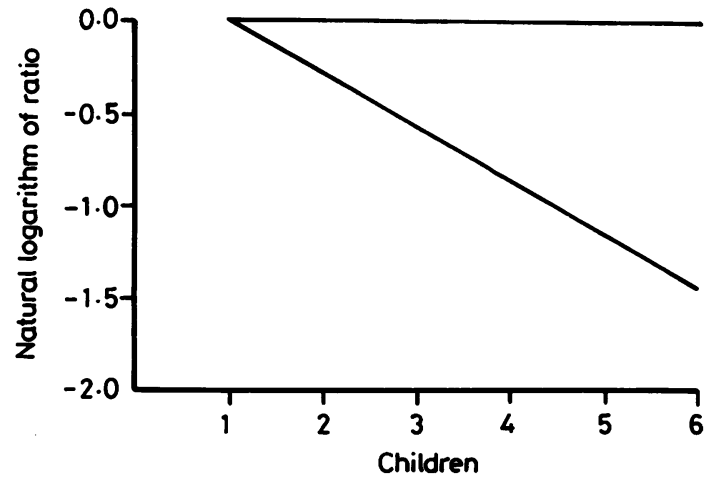

FIG 1 The number of affected families with $n$ offspring can be divided by the number with one offspring. The resulting value can be expressed as a ratio to the proportion of families in the total population which have $n$ or more children. The natural logarithm of the expectation of this ratio will remain at 0 for all values of $n$ if the condition has an environmental aetiology, but will decrease with slope 0.287 (lower line) if the condition is autosomal recessive and the deterrent effect is complete.

PARTIAL DETERMENT

If parents are partially deterred from further childbearing by the birth of an affected child, this will tend to lower the segregation ratio obtained using conventional methods of segregation analysis, since there will be a deficiency of foreborn affected sibs. However, a reliable estimate of the segregation ratio can be derived by looking at afterborn sibs only, that is, sibs born after the first affected child. Comparison of the segregation ratios derived in these two ways may give an indication of a deterrent effect.

Other methods which can be used to try to demonstrate a deterrent effect include the following.

(1) Asking the parents. Surveys of this nature tend to be subject to bias since it is probable that only the more motivated, and therefore the more concerned, respond to questionnaires. Surveys on attitudes of patients ascertained through genetic clinics $^{34}$ and lay societies ${ }^{5}$ have indicated that many couples at high risk are deterred by the prospect of having a child with a long term handicap.

(2) Comparison of the observed and expected number of offspring born after the first affected child in each sibship. Expected numbers can be calculated from knowledge of the general population sibship distributions. The observed and expected values can be compared for significance using a $\chi^{2}$ test.

(3) Comparison of observed sibship sizes and 
distribution of affected children in the sibships with expected values assuming a partial deterrent effect. Expected proportions of sibship size for different levels of deterrent effects are summarised in table 1. Comparison of observed proportions with expected values would permit an estimate of the 'average' deterrent effect.

EXAMPLES FROM PHENYLKETONURIA

The sibships of all cases of phenylketonuria living in the area served by the Trent Regional Neonatal Screening Laboratory were surveyed, selecting (fig 2) only families where the first affected child had been detected by neonatal screening (either urine testing at six weeks or blood testing at six days), and who was born from 1963 onwards. Sibships where the last child was born within the last five years were also excluded, since these families may not have been completed, except where the parents had separated permanently or the mother had been sterilised. Children born from previous or subsequent unions were disregarded.

Several points are suggestive of a deterrent effect.

TABLE 1 Proportions (\%) of sibships of different sizes expected for autosomal recessive inheritance and different deterrent levels, given the values of $r_{1}, r_{2}$, and $r_{3}$ listed in the text. For deterrent levels of 25 to $75 \%$ it is assumed that there will be a $100 \%$ deterrent effect after two affected children. Observed values in the phenylketonuria sibships are included for comparison.

\begin{tabular}{llllll}
\hline $\begin{array}{l}\text { Deterrent } \\
\text { effect }(\%)\end{array}$ & \multicolumn{2}{l}{ Sibship size $(\%)$} & & $\begin{array}{l}\text { Ratio of Ist to } \\
\text { 2nd affected in } \\
\text { sibships of size wo } \\
\text { with ome affected }\end{array}$ \\
\cline { 2 - 6 } & $I$ & 2 & 3 & 4 & 1 \\
\hline 0 & 13 & 53 & 25 & 9 & 1 \\
25 & 19 & 50 & 26 & 5 & $0 \cdot 64$ \\
50 & 31 & 45 & 21 & 4 & $0 \cdot 37$ \\
75 & 42 & 39 & 15 & 3 & $0 \cdot 16$ \\
$1(0)$ & 53 & 34 & 11 & 3 & \\
Phenyl- & & & & & \\
ketonuria & 16 & 48 & 30 & 6 & $0 \cdot 64$ \\
sibships & & & & &
\end{tabular}

(1) Segregation analysis using the maximum likelihood method appropriate for complete ascertainment (table 2) gives a value of $p=0.205 \pm$ $0 \cdot 045$. However, the segregation ratio among sibs born after and excluding the first case in each sibship $=0.286 \pm 0.650$ (14 affected and 35 normal).

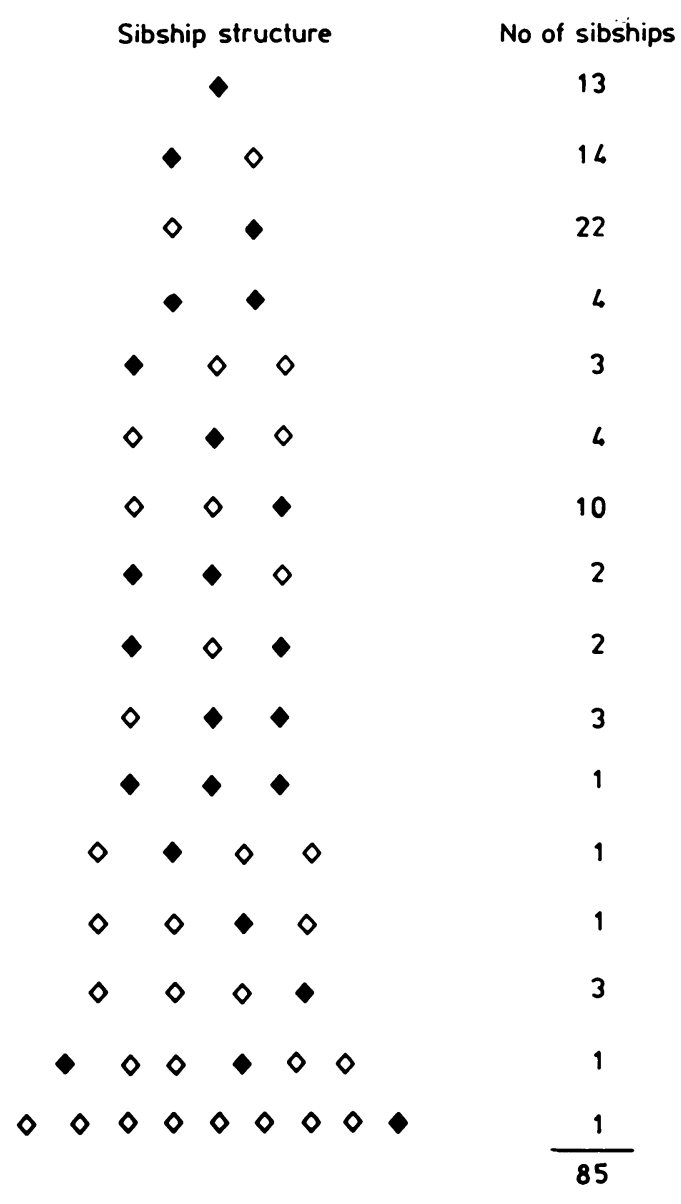

FIG 2 Structure of the 85 sibships ascertained in the study.

TABLE 2 Phenylketonuria families: segregation ratio by maximum likelihood method.

\begin{tabular}{|c|c|c|c|c|c|c|c|c|}
\hline \multirow{2}{*}{$\begin{array}{l}\text { Sibship } \\
\text { size }\end{array}$} & \multirow{2}{*}{$\begin{array}{l}\text { No of } \\
\text { sibships }\end{array}$} & \multicolumn{4}{|c|}{ No of affected } & \multicolumn{3}{|c|}{ Reciprocal of variance } \\
\hline & & Observed & $\begin{array}{l}\text { Expected } \\
(p=0 \cdot 2(0)\end{array}$ & $\begin{array}{l}\text { Expected } \\
(p=0 \cdot 225)\end{array}$ & $\begin{array}{l}\text { Expected } \\
(p=0 \cdot 2.5)\end{array}$ & $p=0 \cdot 20$ & $p=0.22 .5$ & $p=0.25$ \\
\hline 1 & 13 & 13 & 13 & 1.3 & & & & \\
\hline 2 & 40 & 44 & $44 \cdot 44$ & $45 \cdot 108$ & $45 \cdot 712$ & $154 \cdot 32$ & $145 \cdot 60$ & $139 \cdot 32$ \\
\hline 3 & 25 & 34 & 30.75 & 31.575 & $32 \cdot 433$ & $204 \cdot 70$ & $194 \cdot 35$ & 187 \\
\hline 4 & 5 & 5 & 6.775 & $7 \cdot(1) 4$ & $7 \cdot 314$ & 64.835 & 61.835 & 59.74 \\
\hline 6 & 1 & 2 & 1.626 & 1.723 & 1.8248 & $23 \cdot 739$ & $22 \cdot 761$ & $22 \cdot(171$ \\
\hline 9 & 1 & $\overline{1}$ & $2 \cdot(179$ & 2.252 & $2 \cdot 4328$ & $42 \cdot 308$ & $4(1) .578$ & 39.258 \\
\hline Total & 85 & 99 & 98.67 & $I(x) \cdot 67$ & 102.7166 & 489.902 & $46.5 \cdot 124$ & 447.389 \\
\hline
\end{tabular}

By linear interpolation $p=0 \cdot 2045 \pm 0 \cdot(045$. 
(2) For the 83 phenylketonuria sibships of size four or less, the distribution of sibship sizes was as shown in table 1 . The ratio of first to second affected for sibships of size two is also given in table 1 . Comparison with expected values points towards a deterrent effect of approximately $25 \%$. (This deviation from a $1: 1$ ratio is not statistically significant, however. See appendix 1 for a discussion of the sample sizes needed to demonstrate a deterrent effect using this statistic.)

(3) The observed total number of children born after the first affected child in each sibship (49) was significantly less $(p<0 \cdot 001)$ than would be expected in the general population $(81 \cdot 31)$. The derivation of these numbers is given in appendix 2 .

\section{Discussion}

Several factors are likely to make it difficult to determine recessive inheritance with newly defined or rare disorders. First, the tendency towards smaller family size means that sibships containing more than one affected child will be increasingly rare. For example, if all couples have only two children then there will be on average six sibships with one affected child for every sibship with two affected. Published reports, however, are likely to be biased in favour of reporting sibships with more than one affected, so that it may be difficult to know whether occasional reports of two affected sibs represent recessive inheritance or another mechanism, such as the tail end of multifactorial inheritance or subtle chromosome abnormalities.

The second factor which makes the establishment of recessive inheritance difficult is family limitation because of disease severity. In this paper we have considered the problems of (1) distinguishing recessive inheritance when the disease is so severe that all parents are deterred from subsequent reproduction by the birth of a first affected child, and (2) showing a partial deterrent effect by which a proportion of families alter their reproductive pattern after the birth of an affected child. For some of the methods presented to satisfy rigorous statistical significance, relatively large numbers of cases have to be ascertained as indicated, for example, in appendix 1. Strictly speaking, recourse should also be made to local data on general population sibship sizes, taking into account social class and ethnicity, although in practice this information will usually not be available.

These exercises are not simply of academic interest since the provision of accurate recurrence risks is of paramount importance, constituting the primary role of the genetics clinic. This problem has been well aired in a recent paper by Fisher $e t a l^{6}$ in which it was noted that there was a shortage of sibs born after cases of Angelman syndrome, raising the possibility that the condition might be autosomal recessive. Clearly a high incidence of consanguinity provides a useful clue in these situations, but increased parental consanguinity is also noted in $\vec{\varnothing}$ multifactorial inheritance, and the relevance of consanguinity in those ethnic groups in which it is के common is often difficult to interpret.

The advent of prenatal diagnosis for disorders such as phenylketonuria and cystic fibrosis using molecular genetic techniques has provided a new tool in the armamentarium of the clinical geneticist. Many will wish to know the likely demand for these of facilities. An estimate of this can be made by simply $\omega$ asking parents but, as already indicated, responses $\vec{\phi}$ may be biased. Since actions speak louder than $\vec{\Phi}$ words, the reproductive behaviour of relevant $\frac{\text { 의 }}{2}$ families in the past is likely to provide a better $\rightarrow$ indicator of the probable uptake of prenatal 3 diagnosis than responses to questionnaires. The methods presented in this paper allow such reproductive behaviour to be analysed and deterrent effects recognised.

The authors are grateful to Mrs P Marston for typing the manuscript and to Dr John Burn for providing a preview of the paper by Dr Fisher and colleagues on Angelman syndrome.

References
1 Emery AEH. Methodology in medical genetics. 2nd ed. Edin-
burgh: Churchill Livingstone, 1986 .
2 Office of Population Censuses and Surveys. Birth Statistics
England and Wales. Series FM1. London: HMSO, 1980: table
4.1 .
Carter CO. Roberts JAF. Evans KA. Buck AR. Genctic clinic.
A follow-up. Lancet 1971:i:281-5.
+ Evers-Kicbooms G, van der Berghe H. Impact of genetic
counselling: a review of published follow-up studies. Clin Genet
$1979 ; 15: 465-74$.
Barwell BE. Pollitt RJ. Attitude des parents vis-a-vis du
diagnostic prenatal de la phenylcetonuric. Arch Fr Pediatr (in
press).
Fisher JA. Burn J. Alexander FW. Gardner-Medwin D.
Angelman (happy puppet) syndrome in a girl and her brother. $J$
Med Genet 1987:24:294-8.

Correspondence and requests for reprints to Dr I D Young, Department of Child Health, Clinical ${ }^{\mathrm{C}}$ Sciences Building, Leicester Royal Infirmary, PO? Box 65, Leicester LE2 7LX.

APPENDIX 1

If a deterrent effect occurs, then among affected $\stackrel{\Phi}{\Phi}$ families with two children there will be more $\stackrel{\mathbb{Q}}{2}$ affected second children than first children. The . 
deviation from a $1: 1$ ratio will increase with the strength of the deterrent effect. How many families would have to be studied in order to find a significant deviation from a $1: 1$ ratio (using a $\chi^{2}$ test with a $95 \%$ confidence limit)? Specifically, how many families would have to be studied to yield a $95 \%$ probability of detecting a significant deviation from a 1:1 ratio for a given deterrent effect? Approximate values for these family numbers are given below.

Deterrent effect (\%) No of families required

$\begin{array}{rr}25 & 550 \\ 50 & 150 \\ 75 & 50 \\ 100 & 20\end{array}$

Thus this statistic requires either a strong deterrent effect or large sample size in order to show significance.

APPENDIX 2

From the England and Wales birth order data for 1980 , probabilities of subsequent child bearing can be calculated:
Parents have

Probability of having

\begin{tabular}{llll}
\hline 2nd & 3rd & 4th & $\begin{array}{l}\text { 5th or } \\
\text { more* }\end{array}$ \\
0.87 & 0.36 & $0 \cdot 11$ & $0 \cdot 06$ \\
& 0.41 & $0 \cdot 13$ & 0.07 \\
& & 0.32 & $0 \cdot 17$ \\
& & & 0.54
\end{tabular}

( ${ }^{*}$ These numbers represent the sum of all children after four.)

Among the phenylketonuria sibships, the first affected child in the sibship was first born in 40 sibships, second born in 30 , third born in 11, fourth born in three, and ninth born in one. The observed numbers of sibs born after these first born cases are compared with expected values assuming no deterrent effect:

Observed

Expected

Affected Normal Total

After:

First born $\quad 11 \quad 28 \quad 39 \quad 56$

$\begin{array}{lrrrr}\text { Second born } & 3 & 6 & 9 & 18 \cdot 3\end{array}$

Third born

Fourth born

Total

14

1

$5 \cdot 39$

$1 \cdot 62$

$81 \cdot 31$

$\chi^{2}=12 \cdot 83, \mathrm{p}<0 \cdot(001$. 